\title{
Measurement and Evaluation of Collaborative Development Level of Higher Education
}

\author{
https://doi.org/10.3991/ijet.v16i01.19723 \\ Qian Liu, Yongzhe Wang $(\bowtie)$ \\ Beijing Institute of Petrochemical Technology, Beijing, China \\ wangyongzhe@bipt.edu.cn \\ Shaoda Kang \\ Hebei Finance University, Hebei, China
}

\begin{abstract}
With the aid of grey correlation theory and technique for order of preference by similarity to ideal solution (TOPSIS), this paper sets up a multidimensional evaluation index system (EIS) for the comprehensive development level (CDL) of China's higher education, and quantifies the state of collaborative development in 2005-2017 with an improved distance collaboration model. The results show that: Being the premises and bases of higher education, the supply subsystem develops much slower than the other subsystems (i.e., participation, output, and environment), and clearly pulls the development of the other subsystems. From 2012 onwards, the subsystems conformed to basically the same trend for the degree of collaboration: The degree of collaboration tended to be stable. There was even a slight dent in overall degree of collaboration between 2012 and 2016. Hence, the overall degree of collaborative development was far slower than the overall degree of development. After more than a decade of development, the degree of development, degree of collaboration, and degree of collaborative development reached basically the same level in 2017. The empirical results shed new lights on the focal points of higher education development in China.
\end{abstract}

Keywords-Higher education, collaborative development, evaluation index system (EIS), improved distance collaboration model

\section{Introduction}

Higher education is an important propeller of social progress and economic growth. Firstly, higher education blesses the educated with the knowledge and skills necessary for improving labor productivity and save production cost. Secondly, higher education trains modern high-tech professionals, providing a strong support to technological innovation. Thirdly, higher education helps to reform the social structure and optimize the cultural environment. Without higher education, it is impossible for a country to modernize science and technology, not to mention realizing social progress or economic growth. 
Since reform and opening-up, China has made remarkable achievements in higher education. In the decade following 1999, the institutions of higher learning (IHLs) opened their doors wider, and shifted from elite education to mass education. On the scale of higher education, China has surpassed India and the United States (US), ranking first in the world for many years. At present, China is working hard to enrich the connotations of higher education, while maintaining the sustained growth of its scale. To coordinate the development and enhance the quality of higher education, all IHLs in China are obliged to optimize its structure, efficiency, and benefits, and adapt to the development of society, economy, and environment [1-5].

This paper aims to objectively evaluate the collaborative development level of China's higher education. Firstly, an evaluation index system (EIS) was designed for the overall development level of higher education. Next, an improved distance collaboration model was developed to measure the degree of development, degree of collaboration, and overall degree of collaborative development of China's higher education and its subsystems, drawing on the technique for order of preference by similarity to ideal solution (TOPSIS), and grey correlation theory.

\section{$2 \quad$ Literature Review}

Many scholars have explored the collaborative development of China's higher education. Through qualitative analysis, Zhang and Wang [6] suggested that competition is the key to the efficient allocation of higher education resources, but excessive competition will undermine the health and sustainability of higher education; the higher education reform in China calls for the paradigm shift from competition to collaborative development, which is widely adopted around the world for structural optimization of higher education. Inspired by the education index system of United Nations Educational, Scientific and Cultural Organization (UNESCO), Sun et al. [7] constructed an EIS and a comprehensive evaluation model for higher education level of Chinese provinces, and empirically evaluated the comprehensive level, demand, supply, enrollment, participation, performance, and output of higher education in each province.

Zhang et al. [8] designed a 7-dimensional EIS for comprehensive development level (CDL) of higher education, and statistically analyzed the CDL of higher education of each Chinese province through partial least squares (PLS)-structural equation modeling (SEM). The results show that the CDLs between the three regions of China have significant differences, i.e., the higher education CDLs of eastern provinces are generally higher than those of central and western provinces; the provinces within each region differ in terms of the CDL of higher education. Drawing on systems theory and synergetics, Liu [9] defined the concept of the collaborative development of regional higher education, empirically examined the collaborative development between the subsystems of regional higher education in China, including scale, structure, quality, and benefits, and divided the collaborative development of regional higher education in China into moderately collaborative development, weakly collaborative development, and weakly uncollaborative development [10-12]. 
From the perspectives of synergetics and systems theory, Liu and Wang [13] created a comprehensive EIS for higher education structure and industrial structure, and employed the collaborative coupling model to investigate the collaboration between the two factors in China; it is learned that the collaboration is precarious on the national level, and vastly different from region to region. Chen and Chen [14] conducted factor analysis on the coordination between higher education and economy in $31 \mathrm{Chi}-$ nese provinces, and drew the following conclusions: The overall degree of coordination between higher education and economy was relatively low in 2005-2014, despite certain improvement; the degree of coordination varied significantly between provinces; each province has unique reasons for the change of coordination degree.

Xue and Liu [15] performed comprehensive integration of the spatial layout of higher education in Beijing-Tianjin-Hebei (BTH) region, and discovered problems in the balance of spatial layout, the rationality of hierarchical structure, and the scientificity of specialty design. Focusing on connotations, overall collaboration, and student experience, Huang and Sun [16] integrated subjective and objective indices into an EIS for provincial higher education in China, and implemented the EIS to measure and evaluate the CDL of provincial higher education, revealing the provincial imbalance and insufficiency of CDLs, the low CDLs in most provinces, as well as the stepped decline in CDL from eastern region, central region, to western region.

The above studies basically rely on the EIS and empirical analysis/model to quantify the current state or degree of coordination of inter- and intra-regional higher education in China, failing to tackle the overall collaborative development of the national higher education system. Taking the CDL of China's higher education as a whole, this paper quantitatively measures the collaborative development levels of the higher education system in China and its subsystems, with improved distance collaboration model based on TOPSIS and grey correlation theory [17-21].

\section{Methodology}

\subsection{EIS construction}

Before empirically analyzing the degree of collaboration of higher education, it is necessary to construct an EIS with indices that scientifically reflect the correlations and features of higher education and its subsystems. In general, the EIS for higher education should have functions like description, interpretation, evaluation, monitoring and prediction [22-24].

To build a pertinent, scientific, unified, comparable, and feasible EIS for China's higher education [22], this paper selects indices from four dimensions, namely, participation, supply, output, and environment, laying the basis for quantifying the collaborative development level of China's higher education and its subsystems. In total, the established EIS include 4 primary indices, which are supported by 10 secondary indices and 33 tertiary indices (Table 1). 
Table 1. The EIS of the CDL of China's higher education

\begin{tabular}{|c|c|c|}
\hline Primary indices & Secondary indices & Tertiary indices \\
\hline \multirow{7}{*}{ Participation } & \multirow{4}{*}{ Scale } & Number of college students per 100,000 people \\
\hline & & Number of colleges per million people \\
\hline & & Number of students per college \\
\hline & & Gross enrollment rate of higher education \\
\hline & \multirow{3}{*}{ Hierarchy } & Proportion of undergraduates in college students \\
\hline & & Proportion of graduate students in college students \\
\hline & & Proportion of general undergraduate colleges in all colleges \\
\hline \multirow{11}{*}{ Supply } & \multirow{3}{*}{ Financial input } & $\begin{array}{l}\text { Higher education expenditure per student (RMB 10,000 yu- } \\
\text { an/student) }\end{array}$ \\
\hline & & $\begin{array}{l}\text { Proportion of national higher education input in gross domestic } \\
\text { product (GDP) }\end{array}$ \\
\hline & & Research fund per teacher \\
\hline & \multirow{3}{*}{ Human input } & Total number of full-time teachers \\
\hline & & Total number of R\&D personnel \\
\hline & & $\begin{array}{l}\text { Proportion of full-time teachers with deputy senior titles and } \\
\text { above in all teachers }\end{array}$ \\
\hline & \multirow{5}{*}{ Material input } & Area per college \\
\hline & & Area of school buildings per student \\
\hline & & Value of fixed assets per student \\
\hline & & Number of books per student \\
\hline & & Value of teaching and research instruments per student \\
\hline \multirow{10}{*}{ Output } & \multirow{4}{*}{ Research benefit } & Number of technological service projects in colleges \\
\hline & & Number of awards for achievements in colleges \\
\hline & & Amount of technology transfer contracts in colleges \\
\hline & & Income of patent transfers in colleges \\
\hline & \multirow{4}{*}{ Knowledge output } & Number of papers published per teacher \\
\hline & & Number of monographs published per teacher \\
\hline & & Number of cited research and consultation reports \\
\hline & & Number of authorized intellectual property rights per teacher \\
\hline & & Number of junior college graduates and above \\
\hline & Talent output & $\begin{array}{l}\text { Proportion of junior college graduates and above in the em- } \\
\text { ployed population }\end{array}$ \\
\hline \multirow{5}{*}{ Environment } & Policy environment & Education fund in state budget \\
\hline & \multirow{4}{*}{ Economic environment } & Household consumption \\
\hline & & Real GDP per capita \\
\hline & & Urban unemployment rate \\
\hline & & Proportion of tertiary industry \\
\hline
\end{tabular}

1) Participation: This subsystem involves 2 secondary indices and 7 tertiary indices. Specifically, the secondary index of scale covers 4 tertiary indices, reflecting the opportunities for Chinese citizens to access higher education in general; the secondary index of hierarchy covers 3 tertiary indices, reflecting the opportunities for Chinese citizens to receive each level of higher education.

2) Supply: This subsystem describes the premises and bases for the operation and development of higher education. There are 3 secondary indices (i.e., human input, 
financial input, and material input), plus 11 tertiary indices. To objectively reflect the level of each input, all indices were measured by per capita values or proportions, except the total number of full-time teachers and the total number of research and development $(R \& D)$ personnel under the secondary index of human input.

3) Output: This subsystem characterizes the achievements and benefits of higher education, and directly mirrors its operating efficiency and development quality. The 3 secondary indices and 10 tertiary indices fully demonstrate the research benefits, research and teaching results, as well as talent cultivation of higher education.

4) Environment: The health and sustainability of higher education hinge on the social and economic environment. To a certain extent, the society and economy could manifest the current state of higher education. In this subsystem, 2 secondary indices, namely, policy and economic environment, and 5 tertiary indices, were chosen to measure the environment of China's higher education.

\subsection{Evaluation process}

In essence, the distance collaboration model uses Euclidean distance to measure the deviation of the actual state of a system from the ideal state, and thus quantify the degree of collaboration of the system. Here, the improved distance collaboration model is coupled with TOPSIS and grey correlation theory to evaluate the collaborative development of China's higher education. The deviation between the current and ideal states of higher education was calculated, and used to derive the exact degree of collaborative development, facilitating the empirical analysis.

Based on the established EIS, the subsystems of the improved distance collaboration model covers four dimensions: Participation, supply, output, and environment. The historical statistics on the tertiary indices of each subsystem were imported to the model to obtain the development level of each subsystem, the degree of collaboration of each subsystem and pull factors between subsystems, as well as the CDL, overall degree of collaboration, and overall degree of collaborative development of higher education.

Standardization of evaluation indices: The indices in the established EIS need to be nondimensionalized to eliminate their dimensional differences. Different types of indices were standardized by different methods.

The benefit indices, whose quality is positively correlated with value, were standardized by:

$$
g_{i s t}=\frac{z_{i s t}-\min _{t} z_{i s t}}{m_{t} z_{i s t}-\min _{t} z_{i s t}}
$$

The cost indices, whose quality is negatively correlated with value, were standardized by:

$$
g_{i s t}=\frac{\max _{t} z_{i s t}-z_{i s t}}{\max _{t} z_{i s t}-m_{t} \min _{i s t}}
$$


The intermediate indices, whose quality is positively correlated with the proximity to the intermediate value, were standardized by:

$$
g_{\text {ist }}=\frac{\max _{t}\left|z_{i s t}-z^{\prime}{ }_{i s t}\right|-\left|z_{i s t}-z^{\prime}{ }_{i s t}\right|}{\max _{t}\left|z_{i s t}-z^{\prime}{ }_{i s t}\right|}
$$

where, $z_{i s t}$ is the $s$-th index of subsystem $i$ in period $t ; z_{i s t}^{\prime} \in\left[\min _{t} z_{i s t}, \max _{t} z_{i s t}\right]$ is the ideal intermediate value or planned optimal value; $g_{i s t}$ is the dimensionless index after standardization, $i=1,2, \cdots, n, s=1,2, \cdots, m, t=1,2, \cdots, k$.

Calculation of Euclidean distance: The positive and negative ideal points of each index in each subsystem were determined based on the historical statistics. The set of positive ideal points and that of negative ideal points are denoted as $G^{+}=$ $\left(g_{i 1}^{+}, g_{i 2}^{+}, \cdots, g_{i m}^{+}\right)$, and $G^{-}=\left(g_{i 1}^{-}, g_{i 2}^{-}, \cdots, g_{i m}^{-}\right)$, respectively. Then, the Euclidean distances between each subsystem and its positive and negative ideal points can be respectively calculated by:

$$
\begin{aligned}
Q_{i t}^{+} & =\sqrt{\sum_{s=1}^{m}\left(g_{i s}^{+}-g_{i s t}\right)^{2}} \\
Q_{i t}^{-} & =\sqrt{\sum_{s=1}^{m}\left(g_{i s}^{-}-g_{i s t}\right)^{2}}
\end{aligned}
$$

where, $g_{i s}^{+}$and $g_{i s}^{-}$are the best and the worst values of the $s$-th index of in subsystem $i$ over the years, respectively; $Q_{i t}^{+}$and $Q_{i t}^{-}$are the Euclidean distances between subsystem $i$ and the positive and negative ideal points in period $t$, respectively.

Degree of development of each subsystem and the overall degree of development of higher education: The degree of development of subsystem i in period $t$ can be calculated by:

$$
q_{i t}=1-\frac{Q_{i t}^{+}}{Q_{i t}^{+}+Q_{i t}^{-}}=\frac{Q_{i t}^{-}}{Q_{i t}^{+}+Q_{i t}^{-}}
$$

where, $\frac{Q_{i t}^{+}}{Q_{i t}^{+}+Q_{i t}^{-}}$is the proximity of subsystem $i$ to the positive ideal point. The closer the $q_{i t}$ value to zero, the lower the degree of development of the subsystem; the closer the $q_{i t}$ value to one, the higher the degree of development of the subsystem.

The overall degree of development of higher education in period $t$ can be calculated by:

$$
q_{t}=\sum_{i=1}^{n} \omega_{i} q_{i t}
$$

where, $\omega_{i}$ is the weight of each subsystem. Here, the value of $\omega_{i}$ is determined by entropy weighting, an objective weighting method.

Deng's degree of grey correlation and pull factors between subsystems: Taking the degree of development of each subsystem as the main sequence or the contrast sequence, this paper calculates the Deng's degree of grey correlation of each subsystem, and then determines the pull factors between the subsystems.

Deng's degree of grey correlation: Let the degrees of development of a subsystem $X_{i}=\left(q_{i 1}, q_{i 2}, \cdots, q_{i t}\right)$ be the main sequence, and those of another subsystem $X_{j}=$ $\left(q_{j 1}, q_{j 2}, \cdots, q_{j t}\right)$ be the contrast sequence, $i, j=1,2, \cdots, n$. First, the main and con- 
trast sequences were nondimensionalized into $y_{i}(l)$ and $y_{j}(l)$, respectively, $l=$ $1,2, \ldots, t$. Then, a grey correlation analysis model can be established as:

$$
\begin{gathered}
\Delta_{j}(l)=\left|y_{i}(l)-y_{j}(l)\right| \\
\gamma_{i j}(l)=\frac{m+\rho M}{\Delta_{j}(k)+\rho M}
\end{gathered}
$$

On this basis, the Deng's degree of grey correlation $\gamma_{i j}$ between sequences $\mathrm{i}$ and $\mathrm{j}$ can be calculated by:

$$
\gamma_{i j}=\frac{1}{t} \sum_{l=1}^{t} \eta_{j}(l)
$$

where, $\Delta_{j}(l)$ is the sequence of absolute differences; $\gamma_{\mathrm{ij}}(\mathrm{l})$ is the correlation coefficient sequence between sequences $\mathrm{i}$ and $\mathrm{j} ; m=\min _{j} \min _{l} \Delta_{j}(l)$ and $M=$ $\max \max _{j}(l)$ are the minimum and maximum absolute differences, respectively; $\rho \in(0,1)$ is the correlation coefficient or resolution coefficient; $t$ is the number of samples or periods.

Pull factors: If the development curve of subsystem $j$ is higher than that of subsystem $i$ (i.e., subsystem $j$ develops ahead of subsystem $i$ ), then the pull factor of subsystem $j$ to subsystem $i$ is $\theta_{i j}=\gamma_{i j}<1$, that is, the pull effect of subsystem $j$ on subsystem $i$ is less than 1 . If the development curve of subsystem $j$ is lower than that of subsystem $i$ (i.e., subsystem $j$ lags behind of subsystem $i$ ), the pull factor of subsystem $j$ to subsystem $i$ is $\theta_{i j}=1 / \gamma_{i j}>1$, that is, the pull effect of subsystem $j$ to subsystem $i$ is greater than 1 .

Degree of collaboration of each subsystem: The positive and negative ideal degrees of development of each subsystem can be respectively determined as:

$$
\begin{gathered}
{q_{i t}^{\prime+}=}^{+} \sum_{j=1}^{n} \omega_{i} \theta_{i j} q_{j t} \\
q_{i t}^{\prime-}=0
\end{gathered}
$$

where, $i, j=1,2, \cdots, n$.

By the Euclidean distance formula, the deviations of the degree of development of each subsystem from the positive and negative ideal degrees of development can be calculated, and used to derive the degree of collaboration of that subsystem:

$$
P_{i t}=\frac{\sqrt{\left(q_{i t}-q_{i t}^{\prime-}\right)^{2}}}{\sqrt{\left(q_{i t}-q_{i t}^{\prime-}\right)^{2}}+\sqrt{\left(q_{i t}-q_{i t}^{\prime+}\right)^{2}}}=\frac{\left|q_{i t}\right|}{\left|q_{i t}\right|+\left|q_{i t}-q_{i t}^{\prime+}\right|}
$$

Overall degree of collaboration and overall degree of collaborative development: The overall degree of collaboration and overall degree of collaborative development of higher education in China can be respectively calculated by:

$$
P_{t}=\sqrt[n]{\prod_{i=1}^{n} P_{i t}}
$$




$$
P Q_{t}=\sqrt{P_{t} \cdot q_{t}}
$$

\section{$4 \quad$ Empirical Analysis}

\subsection{Data selection and measuring results}

Table 2. The overall degree of development of higher education and the degree of development of each subsystem

\begin{tabular}{|c|c|c|c|c|c|}
\hline Year & $\begin{array}{c}\text { Degree of } \\
\text { development of } \\
\text { participation }\end{array}$ & $\begin{array}{c}\text { Degree of } \\
\text { development of } \\
\text { supply }\end{array}$ & $\begin{array}{c}\text { Degree of } \\
\text { development of } \\
\text { output }\end{array}$ & $\begin{array}{c}\text { Degree of } \\
\text { development of } \\
\text { environment }\end{array}$ & $\begin{array}{c}\text { Overall degree of } \\
\text { development }\end{array}$ \\
\hline 2005 & 0.2354 & 0.3719 & 0.1651 & 0.1532 & 0.2394 \\
\hline 2006 & 0.2600 & 0.3802 & 0.1998 & 0.2518 & 0.2653 \\
\hline 2007 & 0.3731 & 0.3554 & 0.1801 & 0.3533 & 0.3270 \\
\hline 2008 & 0.4754 & 0.2270 & 0.2896 & 0.2489 & 0.3902 \\
\hline 2009 & 0.5114 & 0.2813 & 0.3635 & 0.2282 & 0.4362 \\
\hline 2010 & 0.5541 & 0.3597 & 0.3444 & 0.3347 & 0.4722 \\
\hline 2011 & 0.5709 & 0.4316 & 0.4279 & 0.4295 & 0.5142 \\
\hline 2012 & 0.5700 & 0.4798 & 0.4874 & 0.5038 & 0.5360 \\
\hline 2013 & 0.5763 & 0.4855 & 0.4931 & 0.5915 & 0.5439 \\
\hline 2014 & 0.6030 & 0.5116 & 0.5470 & 0.6183 & 0.5765 \\
\hline 2015 & 0.6688 & 0.5705 & 0.7092 & 0.7478 & 0.6641 \\
\hline 2016 & 0.7425 & 0.6296 & 0.7883 & 0.8522 & 0.7374 \\
\hline 2017 & 0.8373 & 0.6578 & 0.8412 & 1.0000 & 0.8136 \\
\hline
\end{tabular}

The statistics on the tertiary indices in 2005-2017 were obtained from official sources, such as China Statistical Yearbooks, Educational Statistics Yearbooks of China, China Labor Statistical Yearbooks, and Statistical Bulletins on Education released by Chinese Ministry of Education. The data on some indices were directly extracted from these sources, and those on some indices were calculated from the data of these sources. In the environment subsystem, the real GDP per capita was calculated based on the constant price in 2005, aiming to eliminate the impact of inflation.

Based on the established EIS, the collaborative development situation of China's higher education was measured by processing the collected statistics through the above-mentioned methods. The measuring results are recorded in Tables 2-4. By entropy weighting, the weights of participation, supply, output, and environment subsystems were determined as $0.60,0.16,0.22$ and 0.02, respectively. During the calculation of Deng's degree of grey correlation, mean normalization was performed on both the main and contrast sequences, that is, each data in the two sequences was divided by the arithmetic mean of the corresponding sequence, and the resolution coefficient $\rho$ of formula (9) was set to 0.5 . 
Table 3. The pull factors between subsystems

\begin{tabular}{|l|c|c|c|c|}
\hline \multicolumn{1}{|c|}{ Subsystem } & Participation & Supply & Output & Environment \\
\hline Participation & 1.0000 & 1.3533 & 1.4395 & 1.5736 \\
\hline Supply & 0.6995 & 1.0000 & 0.6545 & 0.6377 \\
\hline Output & 0.6258 & 1.6060 & 1.0000 & 0.7179 \\
\hline Environment & 0.6087 & 1.5672 & 1.3344 & 1.0000 \\
\hline
\end{tabular}

Table 4. The degree of collaboration of each subsystem and overall degree of collaborative development of higher education

\begin{tabular}{|c|c|c|c|c|c|c|}
\hline Year & $\begin{array}{c}\text { Degree of } \\
\text { collaboration of } \\
\text { participation }\end{array}$ & $\begin{array}{c}\text { Degree of } \\
\text { collaboration } \\
\text { of supply }\end{array}$ & $\begin{array}{c}\text { Degree of } \\
\text { collaboration } \\
\text { of output }\end{array}$ & $\begin{array}{c}\text { Degree of } \\
\text { collaboration of } \\
\text { environment }\end{array}$ & $\begin{array}{c}\text { Overall } \\
\text { degree of } \\
\text { collaboration }\end{array}$ & $\begin{array}{c}\text { Overall degree } \\
\text { of collaborative } \\
\text { development }\end{array}$ \\
\hline 2005 & 0.8464 & 0.6633 & 0.7469 & 0.6672 & 0.7273 & 0.4173 \\
\hline 2006 & 0.8411 & 0.6799 & 0.8269 & 0.9952 & 0.8282 & 0.4688 \\
\hline 2007 & 0.9887 & 0.7601 & 0.6548 & 0.8372 & 0.8012 & 0.5119 \\
\hline 2008 & 0.9202 & 0.8096 & 0.9538 & 0.7767 & 0.8619 & 0.5799 \\
\hline 2009 & 0.9601 & 0.8944 & 0.9563 & 0.6195 & 0.8446 & 0.6070 \\
\hline 2010 & 0.9583 & 0.9566 & 0.9060 & 0.8369 & 0.9131 & 0.6566 \\
\hline 2011 & 0.9754 & 0.8844 & 0.9924 & 0.9533 & 0.9505 & 0.6991 \\
\hline 2012 & 0.9244 & 0.8454 & 0.9301 & 0.9574 & 0.9133 & 0.6997 \\
\hline 2013 & 0.9199 & 0.8467 & 0.9322 & 0.8519 & 0.8869 & 0.6945 \\
\hline 2014 & 0.9052 & 0.8498 & 0.8999 & 0.8645 & 0.8796 & 0.7121 \\
\hline 2015 & 0.8637 & 0.8675 & 0.8298 & 0.8451 & 0.8514 & 0.7519 \\
\hline 2016 & 0.8634 & 0.8711 & 0.8289 & 0.8302 & 0.8482 & 0.7908 \\
\hline 2017 & 0.8862 & 0.9070 & 0.8410 & 0.7926 & 0.8556 & 0.8343 \\
\hline
\end{tabular}

\subsection{Result analysis}

In 2005-2017, the degree of development of each subsystem exhibited a clear upward trend. From the level in 2005, the degree of development of participation, supply, output, and environment in 2017 increased by 2.56, 0.77, 4.09 and 5.53 times, respectively, with an annual mean growth rate of $11.72 \%, 6.29 \%, 15.83 \%$, and $19.44 \%$, respectively. Except for supply, all subsystems achieved a rapid annual growth faster than $10 \%$. Besides, the degree of development curve of supply was lower than that of participation, output, or environment. The above results show that supply develops much slower than the other subsystems. Thanks to the balanced, sustained, and high-speed growth of the subsystems, the overall degree of development of higher education is bound to increase rapidly and continuously, and the collaborative development of higher education is promoted substantially. 


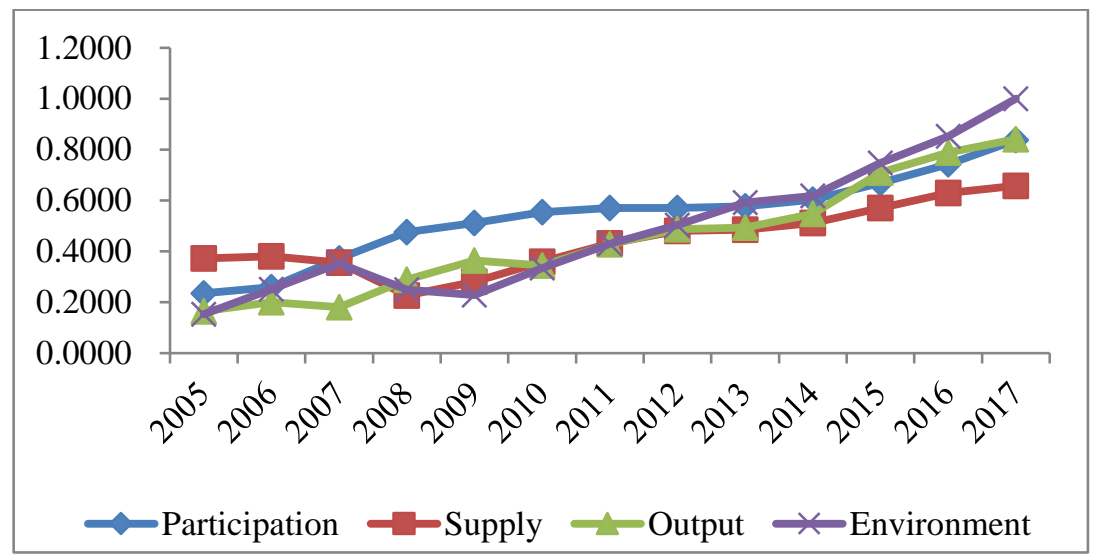

Fig. 1. The degree of development of each subsystem

As shown in Table 3, supply had a significant pull effect on other subsystems of higher education. The pull factors of supply for participation, output and environment subsystem were $1.3533,1.6060$, and 1.5672 , respectively, all of which were greater than 1. Being the premises and bases of higher education, the supply of fund, manpower, and material is a major driver of the participation, benefit, and environment of higher education. In return, the pull factors of supply, output, and environment for participation were $1.3533,1.4395$, and 1.5736 , respectively, all of which were greater than 1 . This means the participation, mainly characterized by scale and hierarchy, is clearly promoted by the other subsystems. Considering the pull factors and the annual growth rates of the subsystems, China should invest more fund, manpower, and material in higher education, to prevent resource bottlenecks, elevate the overall degree of collaborative development, and promote the all-round coordination of higher education.

During 2005-2017, the degree of collaboration of each subsystem changed in two phases: Before 2012, all subsystems witnessed significant fluctuations in the degree of collaboration, and differed greatly in the change direction of that degree. From 2012 onwards, the subsystems conformed to basically the same trend for the degree of collaboration: the degree of collaboration tended to be stable, with limited increase or decrease. The stable trend in the latter phase is attributable to the implementation of the Enhancement Plan for the Innovation Ability of IHLs (2011 Plan) and the emphasis on the connotations of higher education. Since 2011, the IHLs in China have maintained sustained growth in number and scale, while attaching greater importance to the supporting systems (e.g., supply, output, environment, and policies) of higher education. 


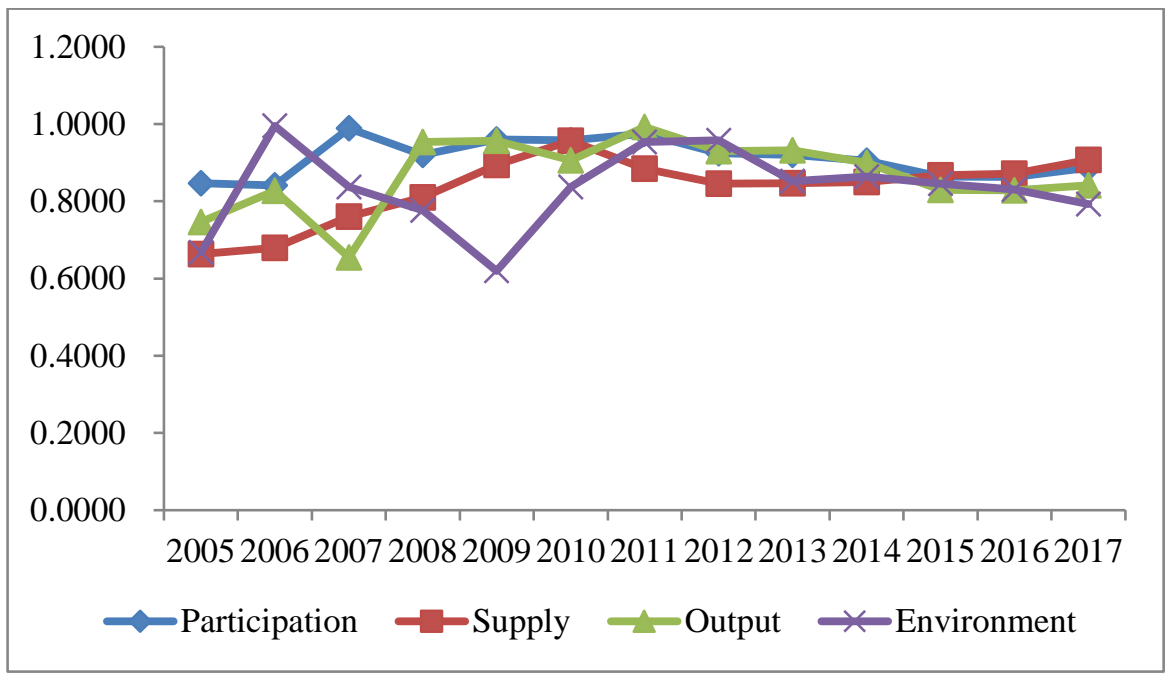

Fig. 2. The degree of collaboration of each subsystem

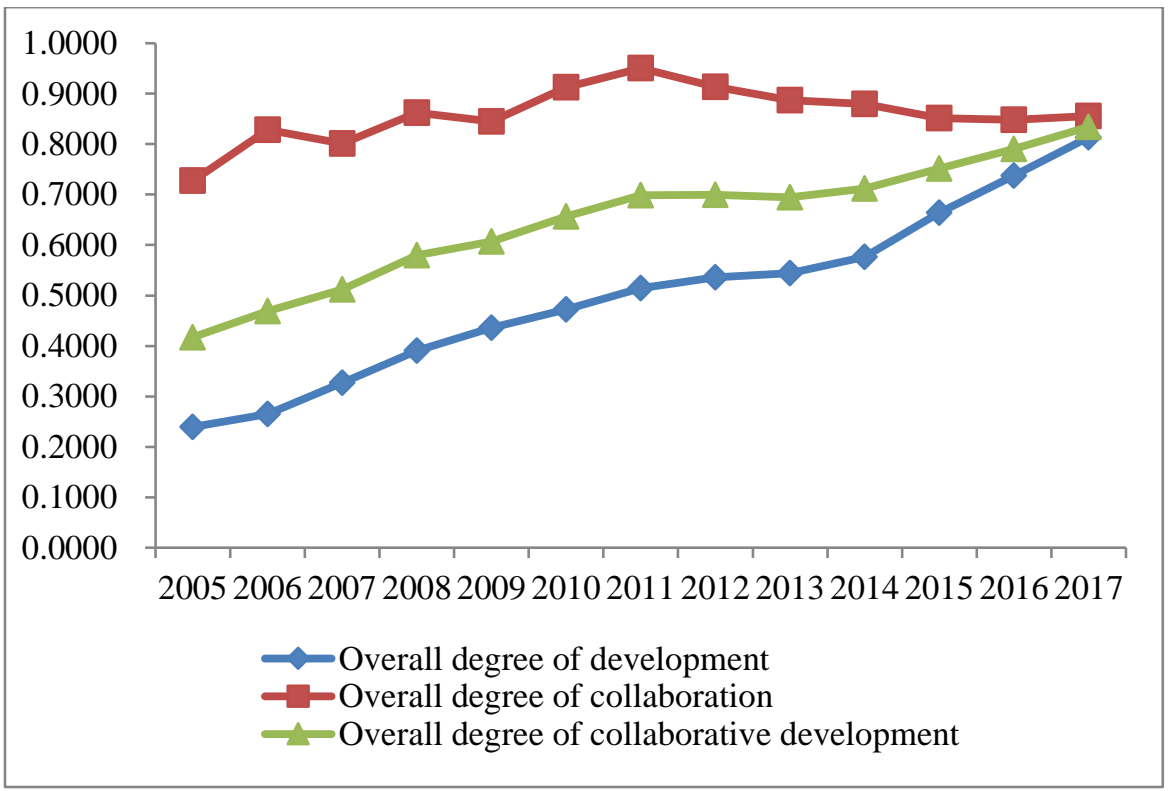

Fig. 3. The trend of collaborative development

In 2005-2017, China's higher education saw obvious growth in the overall degree of development and the overall degree of collaborative development, which increased by 2.40 times and nearly 1 time, respectively. The annual mean growth rates of the overall degree of development and the overall degree of collaborative development were $10.88 \%$ and $6.02 \%$, respectively. 
By contrast, the overall degree of collaboration increased by only $17.64 \%$ in 2017 from the level of 2015, and remained basically stable through the sample period. There was even a slight dent between 2012 and 2016. Hence, the growth rate of the overall degree of collaborative development was far slower than that of the overall degree of development.

After more than a decade of development, the degree of development, degree of collaboration, and degree of collaborative development reached basically the same level in 2017, respectively $0.8136,0.8556$, and 0.8343 . Apart from continued structural optimization, China should input more resources in higher education to pull the development of other subsystems, deepen the collaboration between subsystems, and thus enhance the overall degree of collaborative development of higher education.

\section{Conclusion}

To measure the development of China's higher education, this paper first designs a four-dimensional EIS, involving such subsystems as participation, supply, output, and environment, and then quantifies the state of collaborative development of China's higher education in 2005-2017, with improved distance collaboration model based on TOPSIS and grey correlation theory. The main conclusions are as follows:

Being the premises and bases of higher education, the supply of fund, manpower, and material is a major driver of the participation, benefit, and environment of higher education. From 2012 onwards, the subsystems conformed to basically the same trend for the degree of collaboration: the degree of collaboration tended to be stable. There was even a slight dent in overall degree of collaboration between 2012 and 2016. Hence, the overall degree of collaborative development was far slower than the overall degree of development. After more than a decade of development, the degree of development, degree of collaboration, and degree of collaborative development reached basically the same level in 2017.

At present, China is working hard to enrich the connotations of higher education. To promote the balanced and coordinated development of higher education, all IHLs in China are obliged to optimize its structure, efficiency, and benefits, and adapt to the development of society, economy, and environment. To improve the operation and allocation efficiency of manpower and resource of higher education, China should invest more fund, manpower, and material in higher education, reform the relevant personnel system and resource sharing mechanism, and establish resource sharing platforms between colleges in and beyond each region. These measures could promote the development of the supply subsystem, which pulls the advancement of the other subsystems, and boosts the overall degrees of collaboration and collaborative development of higher education.

\section{Acknowledgement}

This study was supported by the Educational reform and research project of Beijing Institute of Petrochemical Technology (YB20191102). 


\section{$7 \quad$ References}

[1] Bie, D.R. (2018). Study on Connotative Development of Higher Education in China. China Higher Education Research, 2018(6): 6-14. https://doi.org/10.16298/j.cnki.1004-3667.20 18.06 .02

[2] Dolan, R.C., Schmidt, R.M. (1994). Modeling institutional production of higher education. Economics of Education Review, 13(3): 197-213. https://doi.org/10.1016/0272-7757(94) $\underline{90008-6}$

[3] Jacobs, B., Van Der Ploeg, F. (2006). Guide to reform of higher education: a European perspective. Economic policy, 21(47): 536-592. https://doi.org/10.1111/j.1468-0327.2006. $\underline{00166 . x}$

[4] Gao, Y., Chen, R.S. (2010). Empirical analysis of the correlation of factors impacting on the scale of higher education based on the gross enrollment rate. Procedia-Social and Behavioral Sciences, 2(2): 4070-4073. https://doi.org/10.1016/j.sbspro.2010.03.642

[5] Huang, F., Jin, L., Sun, X. (2009). Relationship between scale of higher education and economic growth in China. Asian Social Science, 5(11): 55-60. https://doi.org/10.5539/ass. $\underline{\mathrm{v} 5 \mathrm{n} 11 \mathrm{p} 55}$

[6] Zhang, J.M., Wang, H.C. (2018). From Excessive Competition to Cooperative Development : the Paradigm Conversion of Higher Education. Journal of National Academy of Education Administration, 2018(9): 26-32.

[7] Sun, J.H., Yang, X.J., Miao, R.N. (2009). An Empirical Research on Colligation Assessment of Regional Higher Education. Science of Science and Management of S. \& T. 2009(12): 122-127.

[8] Zhang, N.X., Wang, S., Sun, J.H. (2014). An Evaluation and Regional Comparison of the Holistic Development of Chinese Higher Education. Educational Research, 2014(5): 2836.

[9] Liu, J. (2014). The Coordinated and Common Development of Regional Higher Education and Its Influence on the Comprehensive Level. Hunan University, 2014.

[10] Eva, M., Gómez-Sancho, J.M., Perez-Esparrells, C. (2017). Comparing university performance by legal status: a Malmquist-type index approach for the case of the Spanish higher education system. Tertiary Education and Management, 23(3): 206-221. https://doi. org/10.1080/13583883.2017.1296966

[11] Rosmala, D. (2012). Study of social networking usage in higher education environment. Procedia-Social and Behavioral Sciences, 67: 156-166. https://doi.org/10.1016/j.sbspro.20 $\underline{12.11 .316}$

[12] Johannesson, J., Yu, P.K.H. (2011). Economic environment of higher education organisations in Uganda. Third World Economic Review, 1(1): 58-66. http://nectar. northampton.ac.uk/id/eprint/4317

[13] Liu, Z.J., Wang, Y. (2016). Synergy between Industrial Structure and Higher Education Structure of China: A Study Based on Provincial. Education Research Monthly, 2016(9): 10-15. https://doi.org/10.16477/j.cnki.issn1674-2311.2016.09.002

[14] Chen, J.J., Chen, X. (2017). Research on the Coordination of Higher Education and Regional Economic Development Level. Contemporary Economics, 2017(13): 111-113.

[15] Xue, E.Y., Liu, A.L. (2018). Policy Research on the Optimization of Higher Education's Layout and Structure in the Beijing-Tianjin-Hebei Region. Journal of Higher Education, 2018(8): 38-44.

[16] Huang, H.J., Sun, J.H. (2018). Research on the Evaluation of the Comprehensive Development Level of Higher Education among Provinces in China. Contemporary Education Sciences, 2018(10): 63-68. 
[17] Bao Z.B. (2017). Construction of the evaluation system of regional agricultural circular economy and TOPSIS application, Environmental and Earth Sciences Research Journal, 4(1): 12-16. https://doi.org/10.18280/eesrj.040103

[18] El-Feky S.F., Abou-El-Enien T.H.M. (2019). Hybrid algorithm for rough multi-level multi-objective decision making problems, Ingenierie des Systemes d'Information, 24(1): 1-17. https://doi.org/10.18280/isi.240101

[19] Chebeň, J., Lančarič, D., Munk, M., Obdržálek, P. (2020). Determinants of Economic Sustainability in Higher Education Institutions. Amfiteatru Economic, 22(54): 462-479. https://doi.org/10.24818/EA/2020/54/462

[20] Liu, M., Zhang, Q. (2019). Evaluation of student performance with predicted learning curve based on grey models for personalized tutoring, International Journal of Emerging Technologies in Learning, 14(13): 157-171. https://doi.org/10.3991/ijet.v14i13.9880

[21] Navarro-Bringas, E., Bowles, G., Walker, G.H. (2020). Embracing complexity: a sociotechnical systems approach for the design and evaluation of higher education learning environments. Theoretical Issues in Ergonomics Science, 21(5): 1-19. https://doi.org/10.10 80/1463922X.2020.1723037

[22] Chu, J.T., Guo, D.X. (2003). A Preliminary Study on the Index System of Higher Education Development in China. Jiangsu Higher Education, 2003(1): 23-25. https://doi. org/10.13236/j.cnki.jshe.2003.01.009

[23] Wang, S.H., Lu, X.L. (2020). Design and application of an evaluation index system for urban development quality of China's sub-provincial cities in the new era. International Journal of Sustainable Development and Planning, 15(3): 327-334. https://doi.org/10.1828 0/ijsdp. 150309

[24] Lv, C.M., Zhang, H., Wang, X., Liu, J.L. (2020). Regional water circulation health evaluation system based on artificial neural network. International Journal of Design \& Nature and Ecodynamics, 15(2): 211-217. https://doi.org/10.18280/ijdne.150211

\section{Authors}

Qian Liu is an assistant researcher and the office director of Department of Physical Education, Beijing Institute of Petrochemical Technology, Beijing 102617, China. She mainly conducts researches on scale and development of higher education, management of physical education in colleges and universities. Email: lqian@bipt.edu.cn .

Yongzhe Wang is an assistant researcher and works as a Master Tutor at Beijing Institute of Petrochemical Technology, Beijing 102617, China. He obtained his doctorate from Capital University of Economics and Business in 2017. His research interests include economic statistics, higher education statistics, national economy, and energy economy.

Shaoda Kang is a professor at Hebei Finance University, Baoding, Hebei 071000, China. His research interests are involved in national economic management, and student's affairs management in colleges and universities.

Article submitted 2020-11-01. Resubmitted 2020-12-12. Final acceptance 2020-12-14. Final version published as submitted by the authors. 